\title{
18F-FDG SYNTHESIS AND QUALITY CONTROL AND COST EFFECTIVENESS IN NUCLEAR MEDICINE CENTER IN KHMC**
}

\author{
Pharm. Ala' A. Khwaj/ NM unit KHMC, Pharm. Faisal M. Al Obied/NM unit KHMC \\ Pharm. Samer M. Ofeshat/DRMS, Pharm. Amjad A. Yazjeen /Farah royal rehab. Center \\ Pharm. Qusai M. Migdadi / DRMS, Physicist. Noorhan O. Al Mahasees/ NM unit KHMC \\ * King Hussien Medical Center
}

\begin{abstract}
The most widely used radiopharmaceutical in the expanding medical imaging technology of Positron Emission Tomography (PET) is 2-[18F]fluoro-2-deoxy-D-glucose (18FDG). The increasing demand for 18FDG requires reliable production in large amounts

In this article we will covers the fludeoxyglucose (18F-FDG) synthesis and quality control procedures and the cost effectiveness in KHMC with emphasis on practical synthesis currently; 18F-FDG is the most successful PET radiopharmaceutical so far.

It's started in Royal Medical Services in 2003 the advancement in synthesis and quality control of 18F-FDG, together with its approval by the US FDA and the availability of reimbursement, are probably the main reasons for the florin of clinical PET over the last 20 years. 18F-FDG can be synthesized by either electrophonic fluorination or nucleophilic fluorination reaction. Nucleophilic fluorination using mannose triflate as precursor and Kryptofix or tetrabutylammonium salts (TBA) is widely used because of higher yield and shorter reaction time.

The quality control requirements of $18 \mathrm{~F}-\mathrm{FDG}$ can be found in United States Pharmacopeia (USP), British Pharmacopeia (BP), European Pharmacopeia (EP) and the Chemistry, Manufacturing, and Controls (CMC) section from United States Food and Drug Administration (US FDA) PET draft guidance documents. Basic requirements include radionuclide identity, radiochemical purity, chemical purity, $\mathrm{pH}$, residual solvent, sterility, and bacterial endotoxin level. Some of these tests (sterility, endotoxins and radionuclide purity) can be accomplished after the 18F-FDG has been released..
\end{abstract}

\section{INTRODUCTION}

$\mathbf{T}$ he radioisotopes delivery system RDS eclipse in KHMC provides a low-cost automated efficient and easy to operate system for the production of PET/CT isotopes (F-18, C-11, N-13 and $\mathrm{O}-15)$ and radiochemical.

In cyclotron unit, the hydrogen gas is ionized under high voltage. These ions are changing direction in magnetic field and accelerated and strikes carbon foil. The ions which stroke the carbon foils loses their electrons and hence changes in to protons then those protons behaves differently in magnetic field and strikes the target. There are two beam lines, The O-18 loaded to the target before operation is changed in to F-18 through

$(\mathrm{P}, \mathrm{n})$ reaction after the end of bombardment.

O-18(p, n) F-18 means:

Stable nuclei can be bombarded with nucleolus (neutrons or protons) this process is referred to as a nuclear reaction.

The nomenclature for nuclear reaction is target nucleus (bombarding particle recoiling particles product nucleus. O-18 bombarded by protons results in F-18 and a neutron.

$18 \mathrm{~F}-\mathrm{FDG}$ is a glucose analogue in which the hydroxyl group on the 2-carbon of a glucose molecule is replaced by a fluoride atom. Like glucose, 18F-FDG is taken up into living cells by facilitated transport and then phosphorylated by hexokinase. Unlike glucose, 18F-FDG cannot undergo further metabolism because the hydroxyl group at the 2-carbon is a requirement for the process. Nevertheless, 18F-FDG is a good indicator of

Glucose uptake and cell viability. The uptake of glucose analogues into living cells

Also depends on modifications of various carbons at different positions.

It has been shown that the specificity of 3deoxyglucose (3-DG) and 4 deoxyglucose (4-DG) towards hexokinase reduced by 100 -fold, hence3DG and 4-DG were not retained inside the cells. Similarly, 3-fluoro-deoxyglucose and 4fluorodeoxyglucose do not accumulate in living cells as much

As 18F-FDG. Although the nucleophilic substitution reaction is more widely used nowadays, the electrophilic fluorination reaction has an important place in the

Synthesis of 18F-FDG.

\section{SYNTHESIS OF 18F-FDG BY NUCLEOPHILIC FLUORINATION}

In our site we use Nucleophilic fluorination to produce FDG Many attempts have been made to develop a nucleophilic substitution for the synthesis of $18 \mathrm{~F}-\mathrm{FDG}$. This included the use of $18 \mathrm{~F}-\mathrm{CsF}$, 18F-Et4NF, and 18F-KHF.in 1986 they have used $\mathrm{K} 222$ as catalyst. The reaction had a consistent yield 
of over $50 \%$ and the reaction time was shortened to 50 min. Nucleophilic substitution is a chemical reaction involving the addition of a nucleophilic molecule (highly negatively charged molecule) into a molecule with a leaving group (electron drawing group attached to the parent molecule through an unstable chemical bond).

Figure (1) is a general scheme for SN2 nucleophilic substitution reaction. The nucleophilic molecule has a high affinity towards the relatively electron deficient

Centre in the parent molecule created by the electron pulling leaving group. As a result, the nucleophilic molecule forms a covalent bond with the parent molecule

And displaces the leaving group. The stereoconfiguration of the parent molecule is also changed.

In the synthesis of $18 \mathrm{~F}-\mathrm{FDG}, 18 \mathrm{~F}$ ion is the nucleophile. The precursor is mannose triflate in which the 1,3,4,6 position carbons of a mannose molecule are protected with an acetyl group and triflate is the leaving group at the 2-carbon. In the presence of Kryptofix 222TM as catalyst and acetonitrile as solvent, $18 \mathrm{~F}$ ion approaches the mannose triflate at the 2-carbon, while the triflate group leaves the protected mannose molecule to form 18F-FDG (figure 2). Although synthesis of $18 \mathrm{~F}-\mathrm{FDG}$ can be carried out in different computer controlled automatic synthesizers, the nucleophilic process proceeds in roughly same stages:

Removal of $18 \mathrm{~F}$ from the 180 - water coming out from the Cyclotron target

Fluorine has a high hydration energy, so water is not a suitable solvent in this synthesis. Polar aprotic solvent such as acetonitile should be used in an SN2 nucleophilic substitution reaction. Since $18 \mathrm{~F}$ - is produced by a $\mathrm{O} 18(\mathrm{p}, \mathrm{n}) 18 \mathrm{~F}-$ reaction, it is necessary to isolate the $18 \mathrm{~F}$ ion from its aqueous environment. The most convenient way to isolate is to use a light QMA (Quaternary ammonium anion exchange) Sep-Pak column (Accell plus QMA SepPakTM). The $18 \mathrm{~F}$ - is retained by or via an ionexchange reaction and allowed the 180 -water to flow through. The retained $18 \mathrm{~F}$ - is then eluted with an acetonitrile solution of Kryptofix and potassium carbonate (figure 4).

In an aqueous environment, any negatively charged ions must be accompanied by positively charged counterparts. Usually, the $18 \mathrm{~F}$ - washed out from the cyclotron target is accompanied by traces of metal ions from the surface of the target body. When passing through the light QMA anion exchange ion, the $18 \mathrm{~F}$ - is retained and the metal ions will be lost in the 180- water. Hence, it is necessary to introduce a positively charged counter ion to restore the $18 \mathrm{~F}$ - reactivity before

Evaporation of residual 180- enriched water. Several types of positively charged counter ions have been used, including large metal ions such as rubidium or cesium; potassium ion complexes by a large ring structure such as Kryptofix 222TM and tetrabutylammonium salts . Kryptofix 222TM is a cyclic crown ether (Figure 5), which binds the potassium ion, preventing the formation of $18 \mathrm{~F}-\mathrm{KF}$. Thus, potassium acts as the counter ion of $18 \mathrm{~F}$ - to enhance its reactivity but Does not interfere with the synthesis.

Since Kryptofix 222TM causes apnoea and convulsion, all automatic synthesis modules have multiple removal steps so that there is only negligible amount of Kryptofix in the final $18 \mathrm{~F}-$ FDG products.
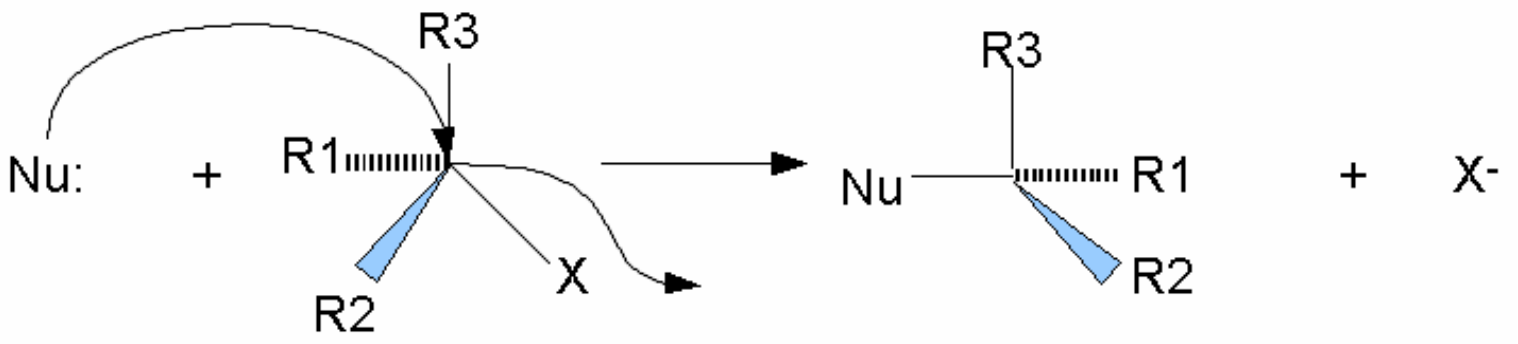

Figure (1) Nucleophilic substitution: $\mathrm{Nu}=$ nucleophilic molecule, $\mathrm{X}=$ leaving group. 


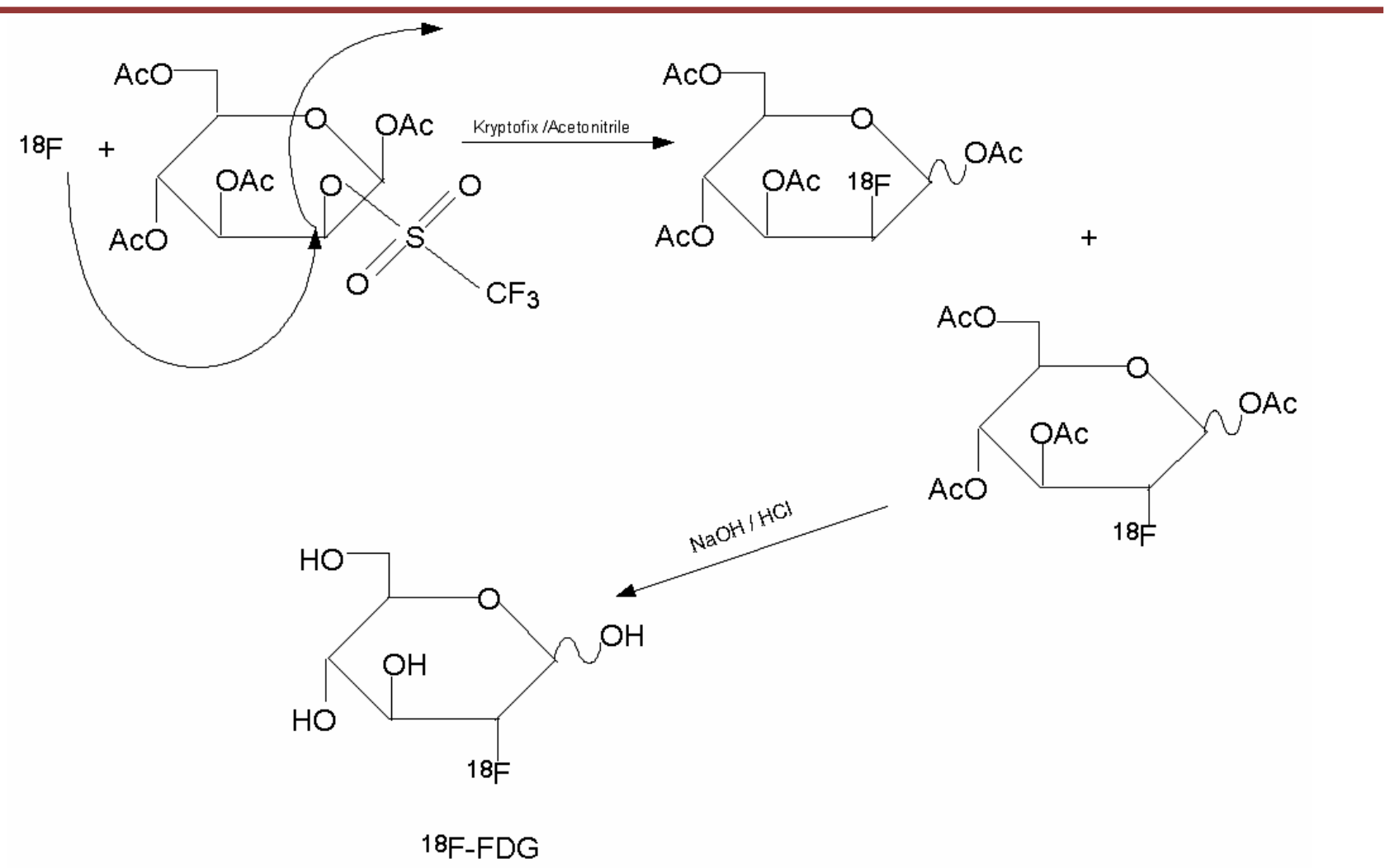

Figure (2) Synthesis of 18F-FDG by nucleophilic substitution.

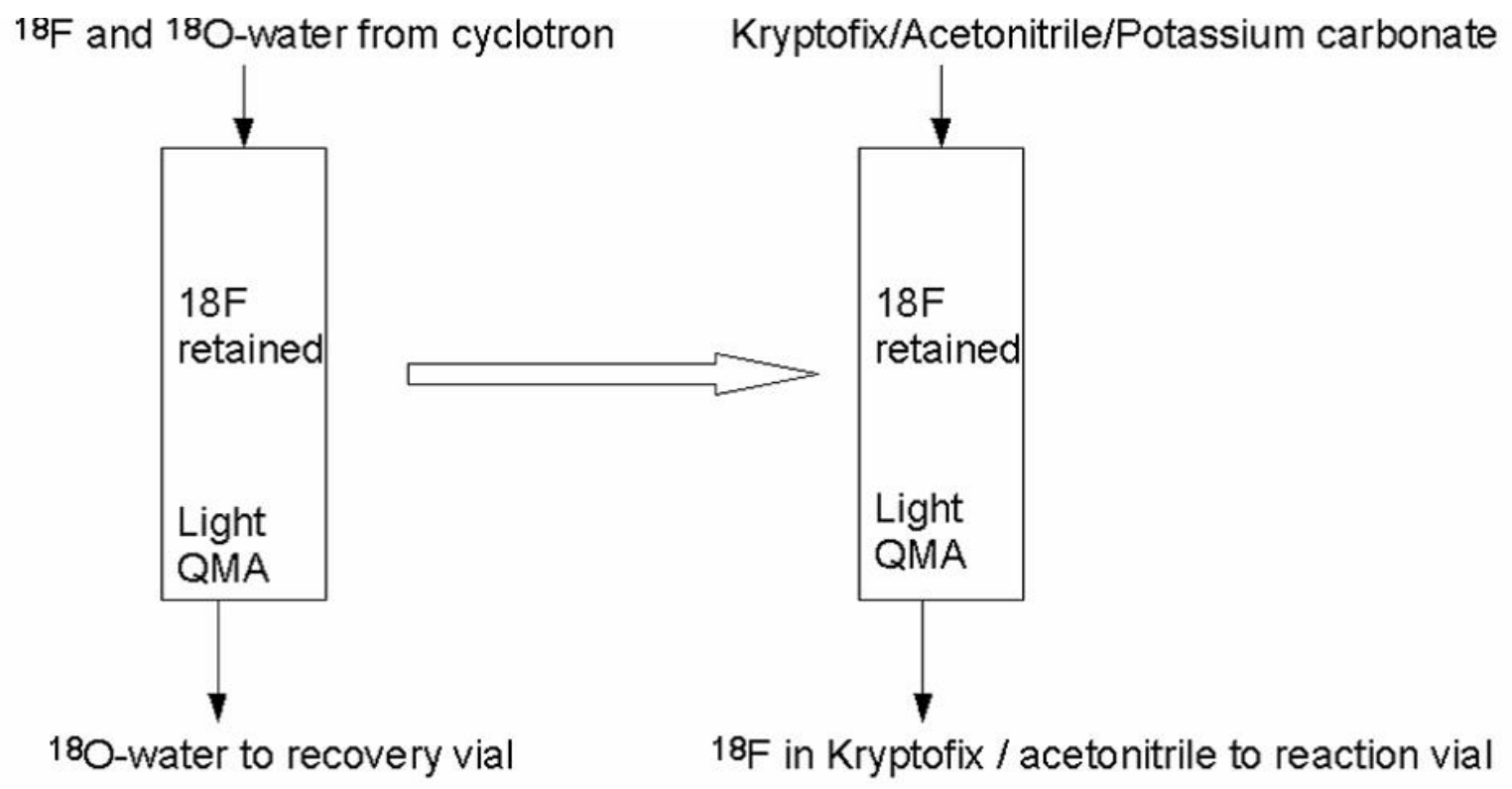

Figure (3 ) (a) Retention of 18F-FDG in light QMA ion exchange column; (b) elution of 18F from light QMA ion exchange column. 


\section{Evaporation of residual 180- water from the $18 \mathrm{~F}$ with Acetonitrile}

After the $18 \mathrm{~F}$ - is eluted into reaction vessel, it is necessary to evaporate any residual water from the solution. The advantage of using acetonitrile as the eluting solvent is that it forms an azeotropic mixture with water. Evaporation of the acetonitrile in a nitrogen

Atmosphere will at the same time remove any residual. The $18 \mathrm{~F}$. Most of the $18 \mathrm{~F}-\mathrm{FDG}$ automatic synthesizers perform the acetonitrile evaporation step several times to

Ensure all the residual 180- water is removed. All components of the synthesis system are also rinsed with acetonitrile to remove moisture. Dry nitrogen (moisture content less than 3 pap) should be used in the synthesis

\section{Addition of mannose triflate into the $18 \mathrm{~F}$ - with Acetonitrile}

The nucleophilic substitution takes place in this stage. After the evaporation of any residual water, the precursor is added to the $18 \mathrm{~F}-$. The choice of precursor depends on the ease of preparation, ease of producing the final product, consistency, yields, and so on. The most commonly used precursor molecule in synthesis of $18 \mathrm{~F}-\mathrm{FDG}$ is $1,3,4$, 6-OAcetyl-2-O-trifluoromethanesulfonyl- beta-Dmannopyranose (mannose triflate). Its structure (Figure 5) is similar to that of FDG, except with a triflate group at the 2 carbon position and acetyl groups at 1,3,4,6 position carbons via ester bonds, which can be readily broken at a higher or lower phi The use of acetyl groups is to protect the hydroxy groups so that fluorination would not occur at these positions. The $18 \mathrm{~F}$ ion approaches the mannose triflate at the 2 position carbon, while the triflate group leaves the protected mannose molecule to form 18F-FDG (Figure 4). After the nucleophilic replacement of the triflate group by $18 \mathrm{~F}$-, the acetyl groups can be easily removed by hydrolysis to give Table (1) :

\begin{tabular}{lll}
\hline & & cost \\
\hline $\mathrm{K} \mathrm{222*}$ & $3 \mathrm{ml}$ & $6.75 \$$ \\
\hline Mannose & $4 \mathrm{ml}$ & \\
\hline Ready column & & $\begin{array}{l}100 \mathrm{mg} / 4 \mathrm{ml} \\
\text { acetonitrile }\end{array}$ \\
\hline
\end{tabular}

rise to $18 \mathrm{~F}-\mathrm{FDG}$ the choice of leaving a group is an important consideration. A good leaving group should have the properties of leaving the parent molecule readily. Once it departs from the parent molecule, its negative charge is stabilized by delocalization and it will not re-enter the parent molecule.

Hydrolysis to remove the protective acetyl groups to Form 18F-FDG

The final step of the synthesis is to remove the protective acetyl groups on the 1,3,4,6 position carbons. This can be accomplished by either using hydrochloric acid (acid hydrolysis) or sodium hydroxide (base hydrolysis). Acid hydrolysis requires a longer time and higher temperature. Base hydrolysis, which is more commonly used currently, is faster and takes place at room temperature. One of the improved base hydrolysis

Is to absorb the 1,3,4,6 acetyl protected $18 \mathrm{~F}$ labeled 2 deoxyglucose on to a $\mathrm{C}-18$ reverse phase column. All other impurities can be removed by rinsing heavily with water. Sodium hydroxide is added to the column so that the base hydrolysis occurs on the column surface. The final $18 \mathrm{~F}-\mathrm{FDG}$ product can be eluted with water while the

unhydrolysed or partially hydrolyzed 1,3,4,6 acetyl protected $18 \mathrm{~F}$ labeled 2 deoxyglucose remains on the column.

\section{Purification of the final $18 F-F D G$ product}

Purification of the final 18F-FDG can be performed with a series of anion exchange column, C-18 reverse phase column and alumina column. Most automatic synthesizers can produce 18F-FDG of over $95 \%$ routinely.

\section{FDG production in $\mathrm{KHMC}$}

In KHMC we use EXPLORA module to produce FDG by nucleophilic substitution, the reagent and consumbles what we supposed to used according to EXPLORA user manual as shown in table (1)

\footnotetext{
*K222 preparation $600 \mathrm{mg}$ cryptand $+110 \mathrm{mg}$ potassium Carbonte which coast $45 \$$ for $20 \mathrm{ml}$ solution .

In our site we change the concentration of kryptofix to be as what we use in CPCU module which cost as shown in table 2 , and we used self prepare column instead of ready column .

Kryptofix solution will be K222 $250 \mathrm{mg} 65 \mathrm{mg}$ potassium in total solution $150 \mathrm{ml}$ coast $20 \$$. in column we use AG11 resin $3 \mathrm{~g}+\mathrm{AG} 501.5 \mathrm{gm}$ +Alumina N sep-pak + C18 sep pak, so in total value we save around $52 \$$ in each production .
} 
With narrow yield to the user manual value and the result of QC was in the range of EuP standard as Table (2) :

\begin{tabular}{lll}
\hline & & cost \\
\hline K 222 & $3 \mathrm{ml}$ & $4 \$$ \\
\hline \multirow{2}{*}{ column } & AG 50 & $1.05 \$$ \\
\cline { 2 - 3 } & AG 11 & $3.6 \$$ \\
\hline
\end{tabular}

\section{QUALITY CONTROL OF 18F-FDG}

The quality requirements of 18F-FDG are set out in various pharmacopoeia including the USP , BP , EP , etc. The US FDA has also published a draft Chemistry, Manufacturing and Controls (CMC) document concerning $18 \mathrm{~F}-\mathrm{FDG}$. It should be noted that the quality control requirements of $18 \mathrm{~F}-\mathrm{FDG}$ differ among these references. An excellent comparison between them can be found elsewhere . In Asia,

Taiwan has established an official guideline for the compounding of PET drug products, as well as for the quality control of 18F-FDG Different countries my adopt a different set of standards. The BP is described in this article solely because this is the shown follows .

standard adopted by the author's country. Table 1 lists the quality control tests required by BP

.Due to short half-life of 18F-FDG, not all the listed tests can be completed before release of the $18 \mathrm{~F}$ FDG product. The BP allows the 18F-FDG to be released before the radionuclide purity test, bacterial endotoxin test, and sterility test are finished. There are other tests not listed in the BP, but may be of significance. The BP Both USP and BP do not list the membrane filter integrity test. However, the test is does not list a test for ethanol, which is widely used in the synthesis of 18F-FDG. Essential as an indirect evidence of the 18F-FDG product sterility because the sterility test result will not be available until much later.
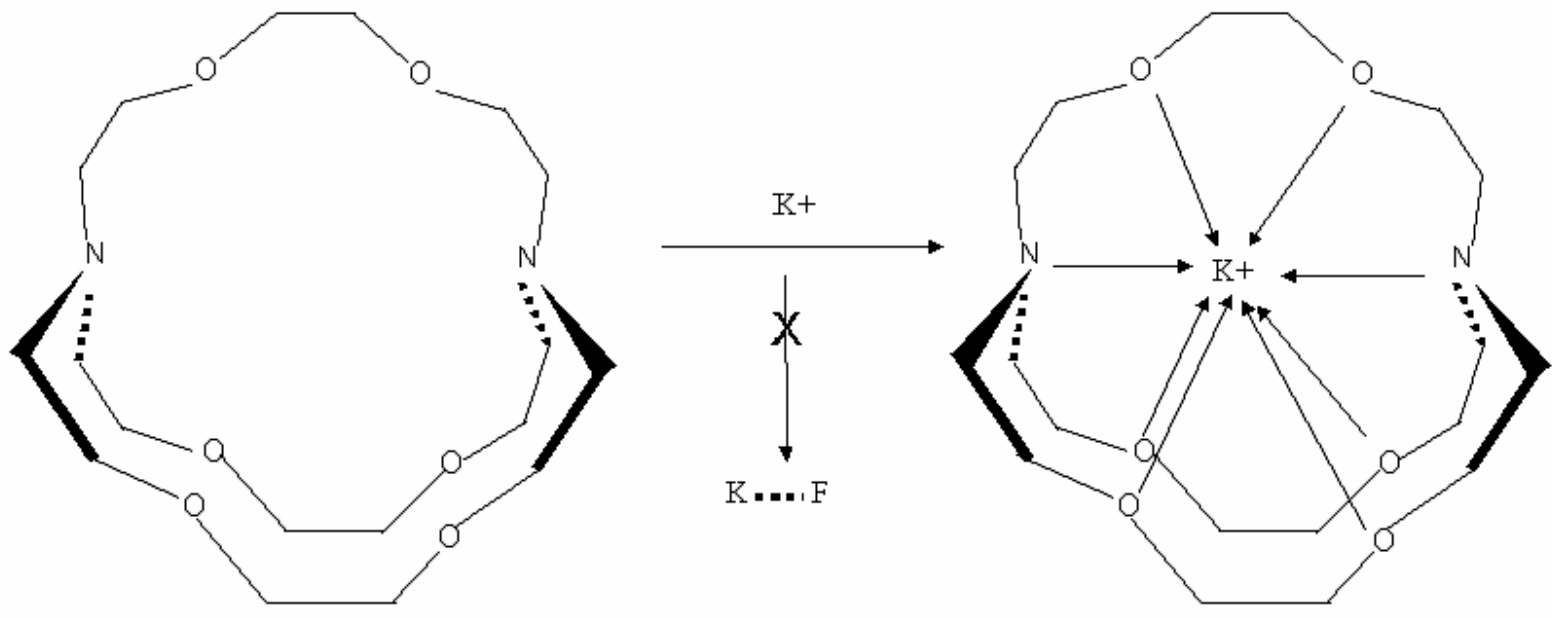

Kryptofix

Figure (4) Kryptofix $222^{\mathrm{TM}}$ and $\mathrm{K}+$. 


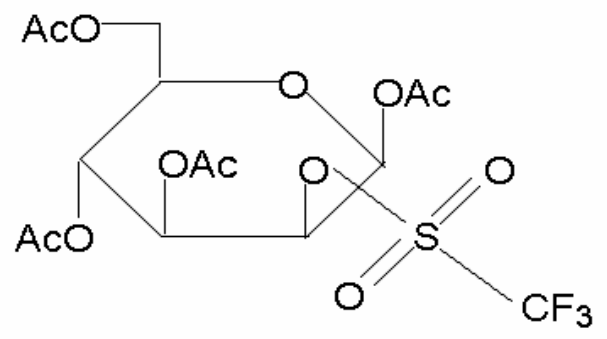

Mannose triflate

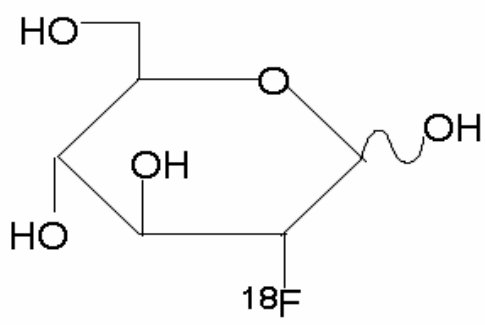

18F-FDG

Figure (5) Structures of mannose triflate and 18F-FDG.

-attachment 1 Quality control form result of standard value

-attachment 2 Quality control form result of our modified version of reagent

-attachment 3 Quality control standard form according to EUP

\section{Conclusion(s)}

FDG production and hence the quality control procedures used to validate the drug Used to validate the drug are the most important issue of this useful drug release.

In addition this cost effective drug is widely applied in the detection and prognosis of cancer at an early stages which elaborate its value in the treatment of the cancerous tissue, hence improving the quality of life for many patients and reflects the sensitivity and the specify of the evaluation of disease

FDG Quality Form

Royal medical services

King Hussein Medical Center

\begin{tabular}{lll}
\hline Test & Method & Standard Result \\
\hline Physically appearance & vision & Colorless/ clear solution \\
& & \\
\hline Radiochemical Identity (Purity) & $\begin{array}{l}\text { Thin layer } \\
\text { chromatography }\end{array}$ & $\begin{array}{l}<95 \% \\
\text { RF }>0.45\end{array}$ \\
\hline Chemical Purity & Gas chromatography GC & $\begin{array}{l}\text { Acetonitil }<0.04 \% \\
\text { Alcohol }<0.5 \%\end{array}$ \\
\hline pH & Litmus Strips & $7.5>$ pH $>4.5$ \\
\hline Bacterial Endotoxin & Limulus Amebocyte & $\begin{array}{l}<0.25 \text { EU/ml usp endotoxin } \\
\text { standards }\end{array}$ \\
\hline Sterility & Lysate & Syptic soybean \\
& $\begin{array}{l}\text { broth/Fluid thioglycolate } \\
\text { medium }\end{array}$ & Sterile \\
\hline
\end{tabular}

*Attachment (1)

FDG Quality Form

Royal medical services

King Hussein Medical Center 


\begin{tabular}{llll}
\hline Test & Method & Standard Result & Results \\
\hline Physically appearance & vision & Colorless/ clear solution & Colorless/clear \\
\hline $\begin{array}{l}\text { Radiochemical Identity } \\
\text { Purity) }\end{array}$ & $\begin{array}{l}\text { Thin layer } \\
\text { chromatography }\end{array}$ & $\begin{array}{l}<95 \% \\
\text { RF }>0.45\end{array}$ \\
\hline Chemical Purity & Gas chromatography GC & $\begin{array}{l}\text { Acetonitil }<0.04 \% \\
\text { Alcohol }<0.5 \%\end{array}$ \\
\hline pH & Litmus Strips & $\mathbf{7 . 5} \mathbf{p H}>\mathbf{4 . 5}$ \\
\hline Bacterial Endotoxin & $\begin{array}{l}\text { Limulus Amebocyte } \\
\text { Lysate }\end{array}$ & $\begin{array}{l}<0.25 \text { EU/ml usp endotoxin } \\
\text { standards }\end{array}$ \\
\hline Sterility & $\begin{array}{l}\text { Typtic soybean } \\
\text { broth/Fluid thioglycolate } \\
\text { medium }\end{array}$ & Sterile \\
& & \\
\hline
\end{tabular}

*Attachment (2)

\section{FDG Quality Form \\ Royal medical services \\ King Hussein Medical Center}

Date: $919 / 2013$ Monday

Production starting time: $\quad 8: 05 \quad A m$

\begin{tabular}{|c|c|c|c|}
\hline Test & Method & Standard Result & Results \\
\hline Physically appearance & vision & Colorless/ clear solution & $\begin{array}{l}\text { Cosbrless } \\
\text { clem }\end{array}$ \\
\hline $\begin{array}{l}\text { Radiochemical Identity } \\
\text { (Purity) }\end{array}$ & Thin layer chromatography & $\begin{array}{l}<95 \% \\
\mathrm{RF}>0.45\end{array}$ & $100 \%$ \\
\hline Chemical Purity & Gas chromatography GC & $\begin{array}{l}\text { Acetonitil }<0.04 \% \\
\text { Alcohol }<0.5 \%\end{array}$ & Pass \\
\hline $\mathrm{pH}$ & Litmus Strips & $7.5>\mathrm{pH}>4.5$ & 6.5 \\
\hline Bacterial Endotoxin & $\begin{array}{c}\text { Limulus Amebocyte Lysate } \\
\text { : }\end{array}$ & $\begin{array}{l}<0.25 \mathrm{EU} / \mathrm{ml} \text { usp endotoxin } \\
\text { standards }\end{array}$ & Pass \\
\hline Sterility & $\begin{array}{l}\text { Typtic soybean broth/Fluid } \\
\text { thioglycolate medium }\end{array}$ & Sterile & sterile \\
\hline
\end{tabular}

FDG Activity $=(1024 . \$ \mathrm{mci}$.

Time of delivery $=(8: 50) \mathrm{am} / \mathrm{pm}$. Production total time $=(77) \mathrm{min}$

Decay corrected yield $=(87 \cdot 2) \%$.

*This is to certify that our FDG product has the above QC values that comply with international standards. 
Metriod: QuickStart

File: 130909-0855.R001

Instrument Parameters

$\begin{array}{ll}\text { Method: } & \text { QuickSlart } \\ \text { Evaluated: } & 09 \text { Sep 2013 09:09:10 } \\ \text { Evaluation by: } & \text { MI } \\ \text { Collimator Type: } & \text { Hi Efficiency } \\ \text { Elect. Resol: } & \text { Normal } \\ \text { Resolution: } & 256 \mathrm{chan} \\ \text { Hi Voltage: } & 1502 \text { Volts } \\ \text { Run Time: } & 3.00 \mathrm{~min} \\ \text { Relative Pos: } & 0.0 \mathrm{~mm} \\ & \end{array}$

File: $\quad$ 130909-0855.FJ01

Width: $\quad 10 \mathrm{~mm}$

Amp. Range: $\quad 50-2047$

Chan Size: $\quad 0.909 \mathrm{~mm}$

Chan of Zero mn: 2.4

ANALYZED BY AMER AL HOURANI

Analysis Parameters

$\begin{array}{llll}\text { Bkg Subtraction: } & \text { none } & \text { Origin: } & 150 \mathrm{~mm} \\ \text { Normalization: } & \text { none } & \text { Front: } & 120.0 \mathrm{~mm} \\ \text { Total Counts: } & 124361.0(41453.7 \text { CPM) } & \text { Region: } & 0.0-200.0 \mathrm{~mm} \\ \text { Total File Counts: } & 124405 & & \end{array}$

Region Analysis

Definition: Peak Search

Peak Slope: $\quad 1.0$ counts $/ \mathrm{mm}$

Min Width: $\quad 11.7 \mathrm{~mm}$

Min pet of Total: $\quad 0.0 \%$

\begin{tabular}{|c|c|c|c|c|c|c|c|c|}
\hline Reg & $\begin{array}{l}(\mathrm{mm}) \\
\text { Start }\end{array}$ & $\begin{array}{r}(\mathrm{mm}) \\
\text { Stop }\end{array}$ & $\begin{array}{r}(\mathrm{mm}) \\
\text { Centroid }\end{array}$ & : & $\begin{array}{l}\text { Region } \\
\text { Counts }\end{array}$ & $\begin{array}{r}\text { Region } \\
\text { CPM }\end{array}$ & $\begin{array}{l}\% \text { of } \\
\text { Total }\end{array}$ & $\begin{array}{l}\% \text { of } \\
\text { ROI }\end{array}$ \\
\hline Rgn 1 & 59.6 & 97.8 & 78.0 & 0.600 & 113605.0 & 378683 & 91.35 & 100.00 \\
\hline
\end{tabular}

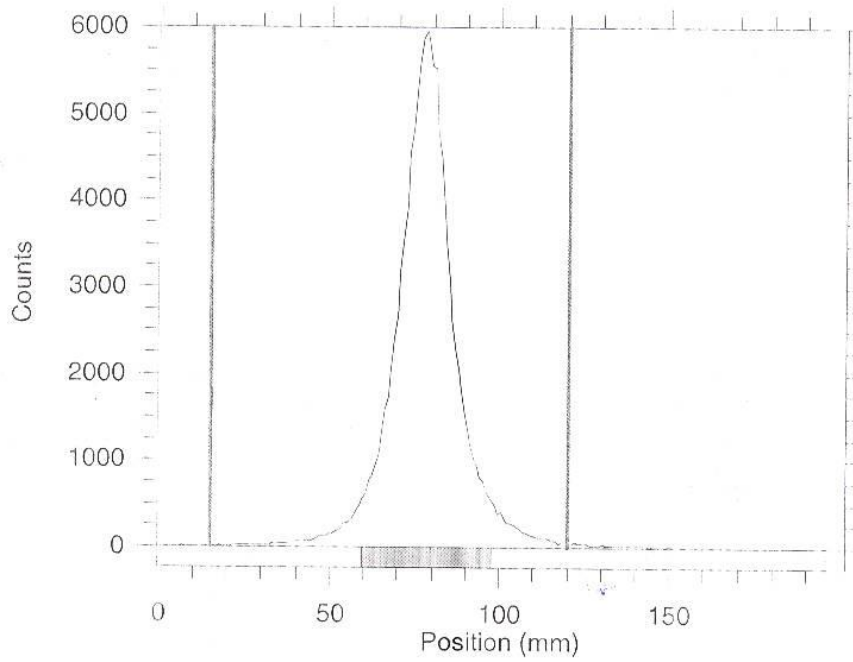

WinScan Ver 3.12

- page 1 -

09-Sep-:1013 09:12 
Data 3 ile $C: \backslash H P C H E M \backslash 1 \backslash D A T A \backslash S I G 13086$.D

ETH $\triangle$ NOL CONC $=0.58$

ACL PONITRILE CONC $=0.04 \%$
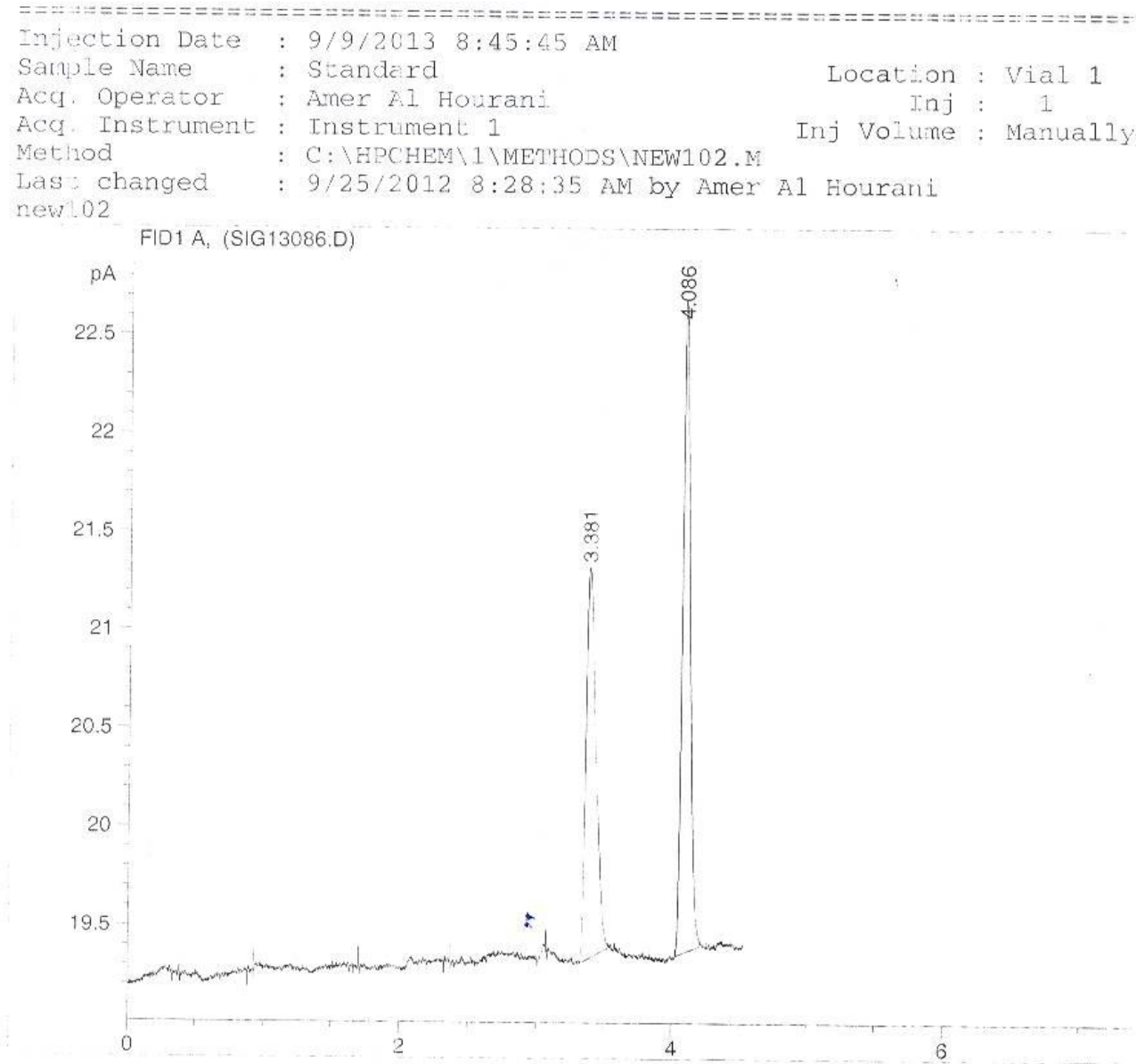

Totals : $\quad 23.01020$

Results obtainea with enhanced integrator!

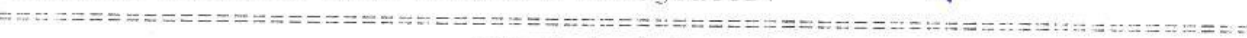
*** End of Report *** 
FDG Quality Form

Royal medical services

King Hussein Medical Center

\begin{tabular}{|c|c|c|}
\hline Test & Method & Standard Result \\
\hline Physically appearance & vision & Colorless/ clear solution \\
\hline $\begin{array}{l}\text { Radiochemical Identity } \\
\text { (Purity) }\end{array}$ & $\begin{array}{l}\text { Thin layer } \\
\text { chromatography }\end{array}$ & $\begin{array}{l}<95 \% \\
\text { RF }>0.45\end{array}$ \\
\hline Chemical Purity & Gas chromatography GC & $\begin{array}{l}\text { Acetonitil }<0.04 \% \\
\text { Alcohol }<0.5 \%\end{array}$ \\
\hline pH & Litmus Strips & $7.5>\mathrm{pH}>4.5$ \\
\hline Bacterial Endotoxin & $\begin{array}{l}\text { Limulus Amebocyte } \\
\text { Lysate }\end{array}$ & $\begin{array}{l}<0.25 \mathrm{EU} / \mathrm{ml} \text { usp endotoxin } \\
\text { standards }\end{array}$ \\
\hline Sterility & $\begin{array}{l}\text { Typtic soybean } \\
\text { broth/Fluid thioglycolate } \\
\text { medium }\end{array}$ & Sterile \\
\hline
\end{tabular}

*Attachment (3)

\section{REFERENCES}

1- Explora FDG4 operating instructions by Siemens

2- Ibrahim. Ghazi. El-habashneh , Medical Cyclotron Technology (2118/6/2012)

3- West,Robert C.CRC handbook of chemistry and physics, Cleveland :CRC press, 1977
4- European pharmacopoeia , third edition .supplement1998, council of Europe ,Strasbourg.

5- CTI Eclipse cyclotron specifications and operating manual 